\title{
Thinking about Urban Density Hypothesis on Ecuadorian Middle Cities
}

\author{
Antonio di Campli \\ Department of Architecture and Arts, Technical University of Loja, Ecuador
}

Copyright $(\mathrm{C} 2016$ by authors, all rights reserved. Authors agree that this article remains permanently open access under the terms of the Creative Commons Attribution License 4.0 International License

\begin{abstract}
This paper proposes some reflection on the definition of urban densification strategies for Ecuadorian middle cities. The objective is twofold. On the one hand it is necessary to determine which in these contexts, are today the conditions under which it is possible and legitimate to prefigure a physical and functional urban space densification process. On the other hand, this research defines specific planning and design actions for a dense regeneration of Ecuadorian middle cities urban spaces. The hypothesis is that the solution of specific urban design problems and the redefinition of some forms of dwelling and social interaction at the proximity scale in more inclusive ways, in Ecuadorian medium sized cities, can be pursued through precise urban space densification strategies focused on the invention of particular devices space of social interaction characterized by a superposition of uses and functions able to define dense forms of use in actually residual spaces.
\end{abstract}

Keywords Ecuador, Urban Densification, Middle Cities, Spatial Justice, Density

\section{Introduction}

The strategic hypothesis [of this work] based on space [...] sets itself up in the clear opposition to the homogenizing efforts of state, of political power, of the world market, and of the commodities world-tendencies [...] which find their practical expression through and in abstract space. [1]

In Ecuadorian middle cities, the solution of specific urban design problems and the redefinition, in a more inclusive sense, of some forms of dwelling and social interaction at the case urban densification strategies focused on the invention of particular spatial 'devices' characterized by a superposition of uses and functions able to define dense forms of uses and social exchanges along actually residual environmental spaces and nets. The term 'device' is intended in a Foucauldian sense as a machinery apparatus, dispositif
$[2,3]$, which enhance different forms of power within the city trying to address, in this case, the question of how notions of just/unjust space relate to issues of densification. The configuration of these devices will help make the urban mosaic of Ecuadorian medium-sized cities more spatially diversified and socially inclusive, configuring the geography of places designed as 'membrane' spaces between neighborhoods inhabited by different social classes.

To support this hypothesis, the following text is articulated in three parts: the first part presents a reflection on some Latin American city characters and problems, the second part describes more precisely contemporary Ecuadorian middle cities problems, the last part identifies some urban densification strategies.

The Latin American city is generally described by architects, planners and social science scholars, as an 'extreme' space marked by persistent and articulated processes of spatial and social fragmentation usually associated with images of indefinite and uncontrollable urban growths [4-7]. Social, historical, political and economic reasons for such processes have been largely investigated especially in social sciences where, both Latin American and European, different traditions and practices of research, have identified a number of elements that we can synthetically order in two large fields.

The first field consists of spatial and territorial figures and issues. The logics construction of Latin American urban spaces are largely the output of its formal matrix described by the figure of the grid or damero [8,9]. It is an abstract, purely geometric space, indifferent to physical and social contexts, conceived as a replicable prototype. The grid is made of lines ideally directed towards infinity, defined by movements rather than figurations. A highly symbolic space whose signs correspond to names or numbers, it does not contain places. The desire of isotropy and the search for egalitarian settlement conditions through the abstraction of the damero is however contradicted, since the times of the first colonizations, by a particular dual condition where the utopian social order of the founded cities confronted itself almost immediately with his double, the indigenous city, 
sometimes planned according to specific social conditions, as in the case of the Jesuit reductions in Paraguay, sometimes built according to regular patterns and symbolic connotations[10].

The principles of separation and dependence, the dual character of the colonial urban space articulated according to the center-periphery structure have been reproduced in larger scale relations. In Latin America the city, is basically the only place where to look for the 'good life' $[11,12]$. This phenomenon causes constant migration of rural populations eager for social redemption to urban areas.

The second field, marked by political themes, is defined by issues of poor democracy in decision-making and management processes and the persistence of colonial forms in the constructions of urban space. In urban contexts inhabited by lower middle or poor classes, redevelopment and regeneration public initiatives aimed at bringing illegally formed districts into formality are hampered by particular forms of resistance to power and authority on the part of social groups that should theoretically benefit from these transformations. It is a resistance strategy expressed through a non-adherence to more regulated forms of dwelling, public action seeks to promote $[13,14]$.

In a context marked by such processes and logics, the social fabric tends 'to decant' in the urban space recomposing itself in layers or homogeneous social groups. If this distinction in the past was mainly linked to ethnic issues (neighborhoods for whites people, mestizos, natives, blacks), what today has gained importance is the economic status although some social groups such as the natives persist in settling in exclusive communities or mingling only with low class mestizos. The result is an urban mosaic where each tile corresponds to specific social groups, urban landscapes, forms of use of the space. These processes of fragmentation, separation and definition of asymmetrical relationships between different parts of the city, identify urban areas where each part has a specific role and character, defined functions and inhabited by a distinct social group.

The place where urban studies and social sciences scholars traditionally observed these phenomena has almost always been the metropolitan city $[15,16]$.

Rio de Janeiro, Buenos Aires, Bogota, Caracas and Lima, were places of investigation and experimentations of complex planning, urban and social design strategies whose successes and failures have been widely debated worldwide. Attention to major centers, to the issues they raise and to the solutions where identified for them, has, indirectly, suggested that in Latin America, the urban question is essentially defined by themes and problems of the metropolis and that the design solutions tested in these areas are substantially exportable in other urban contexts [17-19].

In recent years, however, phenomena such as the political stability of the continent, the general improvement of economic conditions, the emergence and consolidation of the middle class, a general increase in infrastructure resources both at urban and territorial scale, are triggering unprecedented changes in the forms and dwelling imaginaries. From the beginning of the Noughties, across the continent it has emerged, in the discourses of various subjects and social groups, architects, urban planners or politicians, a desire for a different urbanity or cityness, an anxious search for new urban space conditions characterized by less rarefied, less divided, more compact and cozier dwelling conditions. The preference for less introverted settlement forms, the affirmation of discourses on urban sustainability, ecology, on the importance of public space, the recovery of old incrementalist housing strategies or the success of urban acupuncture experimentations, basically insist, using different arguments or objectives, on the search for a more 'dense' urban space.

At the same time, in many Latin American contexts it is possible to assist to a change in the settlement arrangement at the territorial scale in a less hierarchical sense characterized by the emergence of networks of medium-sized centers that are triggering phenomena of regionalization of economies as well as of territories.

One of the territories where these phenomena are more visible is Ecuador, a country characterized by a settlement structure arranged according to 'cantonal' logics, supported by an articulated network of medium-sized cities. In Ecuador, this category includes cities with 200,000 and 400,000 inhabitants. Examples are cities such as Riobamba, Ibarra, Ambato, Loja, Machala and, under certain aspects, Cuenca.

This settlement frame, since the early 2000 s, following the triggering of migratory inflows from rural areas and the return of previously emigrated abroad families, has acquired a growing strength, unexpectedly capable, in many ways, to balance the might and the attractive power of the couple Quito - Guayaquil, cities with approximately three million inhabitants, respectively, the political and economic capital of the country [13].

Processes of growth and urban transformations that have characterized in recent years Ecuadorians middle cities tend to present themselves as more controllable than those featuring larger centers as middle cities appear to be less marked by phenomena of uncontrolled expansion of residential suburbs, urban violence and social insecurity that traditionally characterize urban landscapes of metropolitan cities. In many cases, these dynamics are not devoid of dysregulations, but medium-sized cities have been able to define less conflictual, although not fully integrated, conditions for cohabitation between different groups and social classes $[10,20,21]$. In particular, contemporary Ecuadorian medium-sized cities' urban growth processes are largely outcome of particular economic speculation phenomena promoted by middle class families and by people immigrated since the early 2000s, in countries like Spain or Italy who, have having improved their economic conditions now decide to come back to Ecuador investing their savings in the construction of residential buildings for their families or to be placed on the housing market as houses to rent. Differently from previous phenomena of urbanization that 
took place in the country, middle class families' investments, from the Noughties onward, are no longer directed solely towards the two major centers of Quito and Guayaquil, but to the network of medium-sized urban centers [13].

However, some specific processes and problems characterize Ecuadorian medium-sized cities.

The first element that acquires relevance here is the presence of well-defined desires and dwelling imaginaries. These visions and practices appear to be more consolidated and therefore less malleable than those characterizing, for example, some dwelling situations that are identifiable in many large cities peripheries. In Ecuadorian middle cities, the ideal, real or imagined, freedom of choice between alternative forms of living that seems possible to invent in the isotropic urban space is almost always denied by the preference given to the typology of the row house in blocks defined by more or less regular grids and road alignments. Forms of construction of new residential areas are marked by incremental spatial and constructive logics, and by the adoption of particularly 'showy' architectural languages. Here the house is image more than space, a device by which the status and economic condition of the family who live there is affirmed. This prevalence of the visual over the spatial describes the competitive and mental character of many Ecuadorian middle cities urban landscapes. The satisfaction and enjoyment that people show with respect to these forms of design and construction of residential spaces are an example of these consolidated dwelling practices and imaginaries $[22,23]$.

A second element is constituted by the fact that the geometric damero informing Ecuadorian middle cities urban spaces, in its informal as well as in its consolidated and central parts, is almost always indifferent to the environmental system which, in this way, is considered as a residual space marked by phenomena such as hydraulic or geological risk, ecological instability and degradation. In the overlap and interaction between the abstract grid and the physical urban 'palimpsest', a friction is produced and the environmental system, in its various articulations such as, hydrographic net, geological jumps, agricultural or forest areas, is redefined as a threshold between parts of the city inhabited by different social groups and classes. But, this residual condition, unexpectedly, in some cases, contains a promise. Urban analyses, surveys and field interviews to inhabitants demonstrated that, often, thresholds are places where it is possible to observe forms of social interaction between different social strata, upper classes and lower classes. These dangerous situations are, in many cases, the only real 'public spaces', this is to say, places where some forms of social interaction, conflicts and exchange, are put in scene.

The relatively small extension of middle-sized cities, moreover, is not accompanied by the definition of polycentric urban structures, on the contrary, here growth phenomena almost always strengthen the tertiary, commercial and administrative roles of consolidated central parts of the city that were already characterized by such features. This phenomenon, associated with an exasperated functional connotation of urban fabric, helps to highlight a third question, the presence of strong commuters' movements between downtown and the suburbs.

A place where these phenomena are easy to observe is Loja, a colonial city located in southern Ecuador of about 200,000 inhabitants, located in an Andean mountain basin corresponding to the Zamora river valley, near the Amazon plains. Loja, unlike other medium-sized cities such as Riobamba or Cuenca, seems to be devoid of particular spatial or urban landscape qualities; therefore it can be considered as a prototypical Ecuadorian middle city. This city, in the last 20 years has transformed itself from a local scale services provider town to an attractive immigration center of rural population from the southern provinces of the country. Loja urban growth processes have been partly regulated and indulged, producing, however, some effects such as an excessive pressure on the colonial central district, the privileged place for trade and service activities, and a poor connotation of new suburbs that can be describes in many parts as pure residential neighborhoods. Investigations on Loja were conducted through urban and social analyses, interviews with local stakeholders and inhabitants that have highlighted some issues on characters, problems and dwelling practices in Loja. [FIG. 01].

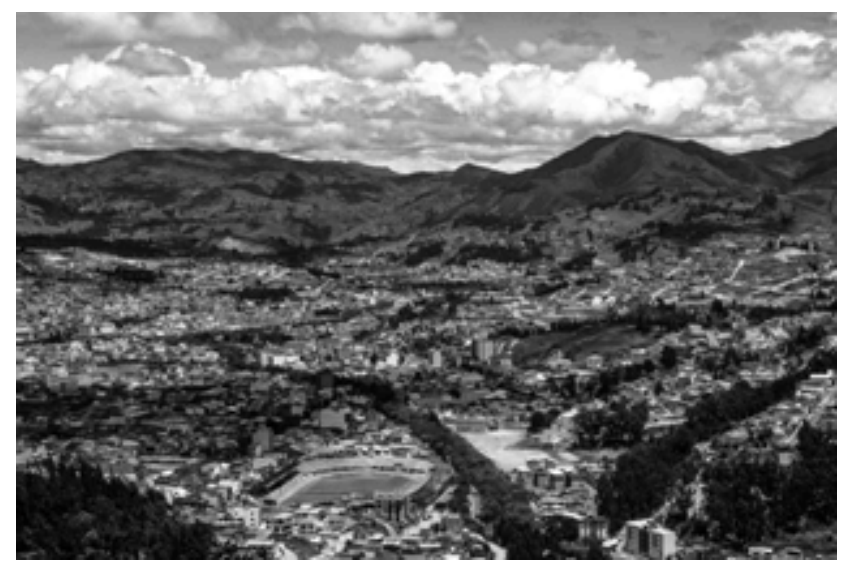

Figure 1. Loja. Aerea View

\section{Silent Dwelling}

It is possible to synthetically describe the Lojan urban space as a composition of specialized places, a space functionally and socially divided, marked by clearly defined both spatially and temporally rhythms and forms of dwelling. In general terms, especially in its peripheral parts, this is an urban space that seems weakly appropriated by inhabitants, only some specific practices such as spots of formal and informal commerce or sport activities mark the space. It is therefore a place where forms of dwellings tend to acquire some extreme characters. It is possible to recognize a dense dwelling, which manifests itself, according to well-defined rhythms in some of its more central parts colonized by a 
variety of forms and commercials practices. At the same time, in most of its exclusively peripheral residential parts, in the richer as well as in poorer ones, a silent and rarified dwelling appears. The public space seems to be substantially considered just an infrastructure for mobility, social interaction practices are evident only in some public or private equipment such as small parks or other welfare amenities.

Separation, alignment, distinction, preeminence of the image over materials and spatial qualities, in its extensive residential parts of the city, urban space, even if it doesn't present particular social insecurity, conditions, offers substantially limited social exchanges opportunities beyond the house front door.

The condition of alienation Lojan dwellers experience in the peripheral built environment they inhabit leads to 'disillusion', which leaves space almost totally blank. A blankness that words convey. Here the consumption of urban landscapes or architecture as pure images dominates. Lojan urban fabric is primarily appreciated and evaluated by way of vision alone, akin to either a thing in a gallery or on a screen, on in an advertisement, rather than the setting in which, especially upper and lower middle-class people, live.

Overall the Lojan urban environment is characterized by spaces that are strange: homogeneous, rationalized, and constrictive. At the same time they are totally dislocated without throughout the Zamora river valley according to some repetitive and banal patterns.

The reward of alienation this urban space offers is less some kind of liberating homogeneity and anonymity, than, it recalls a paradoxical situation made up of the dissolution of formal boundaries between 'felicity' and 'misery', and the harsh separations, found in 'public facilities' blocks of terraced houses, 'dwelling environments', that are divided and assigned in isolated fashion to unconnected sites, in spaces which are themselves specialized.

The silent form of dwelling that arises from this situation is set apart from consciousness as a matter of necessity.

Finding a purpose for urban design here is exceedingly difficult; architecture here is just an excess value, an urban adornment or icon. In this context, the expansion of the city is still conceived and realized according to implicitly colonial logics, as an automatic and uncritical repetition of abstract geometrical grids or importation of landscapes. This approach transforms buildings and neighborhoods into commodities, products. This urban environment includes widespread disregard for the everyday life and is threatened with dissolution.

\section{On the Surface: Repetition Everywhere}

Carefully observing Loja, its outskirts and its newer parts, it is possible to affirm that everything here resembles everything else. Urban fabrics, residential typologies, spatial patterns, are repetitive and reproduced as stamps on paper. Such sameness analogizes both abstraction and control, leading toward a degree of indistinguishability between architecture and the city that seems pervasive.

Here everything is cyclical repetition through linear repetition.

Repetition is not a consequence of incompetence, or even a poverty of imagination, but rather is rendered inevitable by a range of spatial practices repeated without reflections. Loja's repetitious urban spaces are the outcome of repetitious gestures (those of architects, planners, dwellers, and property developers) associated with two instruments which are both duplicatable and designed to duplicate: the damero and the row house. On the surface, the dominance of repetition could be construed as simply the product of atrophied imaginations. Such a view though holds the myth of expertise in reserve, while setting aside the possibility that it is space as a product, subject to economies of scale in production, reproducible and attaining its greatest value by being an exchangeable commodity that overwhelmed the use value of space. In this sense, the quantifiable trumps the qualitative: are these spaces interchangeable because they are homologous? Or are they homogeneous so that they can be exchanged, bought and sold, with the only differences between thumbing those assessable in money, i.e. quantifiable terms? Whether or not one believes that repetition is a result of a certain similarity between these spaces or a requirement of their status as objects, what is certain is that in Loja repetition reigns supreme.

An urban space of this kind is a product strictu sensu: it is something reproducible, the consequence of repetitive behaviors. Reproducibility, abstraction and quantifiability, the visual dominates the realm of products, akin to the importance of package designing the appeal and sale of products.

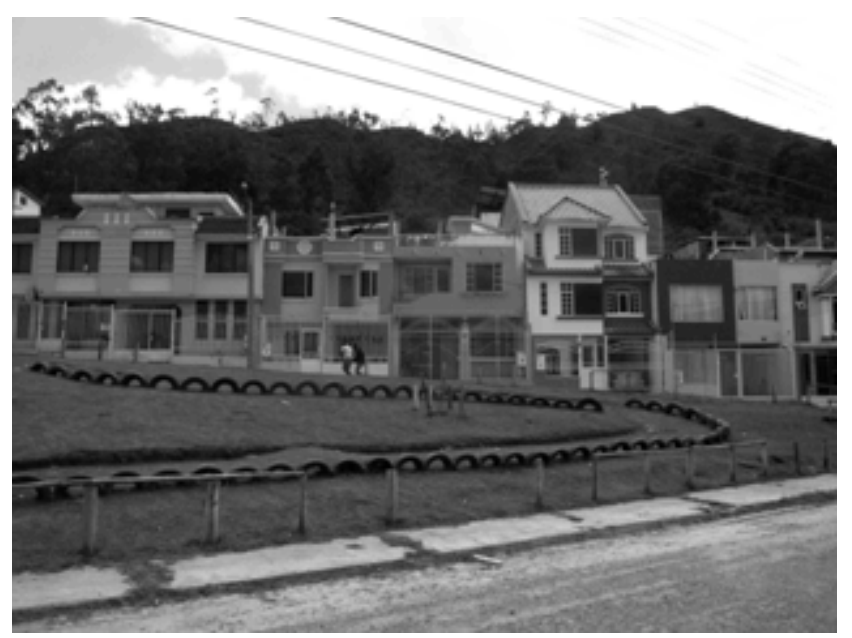

Figure 2. Loja. Los Rosales District

What characterizes many of Loja peripheral urban settings is their pronounced visual appearance. They are made with the visible in mind: the visibility of status, people and things, of spaces, and of whatever is contained by them. The predominance of visualization conceals repetitiveness. 
People look and take sight, take seeing for life itself. People here build on the basis of images.

It is in this condition characterized by persistent colonial spatial logics, by the absence of an articulated and diversified urban space, the home becomes a complex universe of overlapping reference, daily rituals, practical needs, tacit desires and ambitions that talk together in architectural space. [FIG. 02].

\section{Overcoming Cartesian (and Cortesian) Logics $^{i}$}

The colonial idea of smooth and geometrical urban space recalls the concept of space as empty as conceived by Descartes and the absolutist tendencies of Cartesian logics. The limitation of these views of space is that they encourage is mainly an abstract mathematical idea of space, which makes consideration about 'social exchange' seem quite weird, fostering an idea of architecture and of urban settings as an autonomous objects in space, positioned mainly for aesthetic appreciation.

Intended in this way, space is decoupled from time, and thus considerations of social life as unfolding in urban space almost disappear. Briefly stated, 'counter-projects' are then here useful then to redefine urban spaces on the basis of its specificities and to bridge the gap between the mental and social realm, between the implicit colonial habits still conforming contemporary dwelling practices and the space of inhabitants who deal with material things. To realize this, the centrality of social life and social practices in discussion about urban space must be recuperated [24].

The endless extension and rigid separation of abstract geometrical spaces, which exhibit a dominant trend toward fragmentation seems a trend subordinated to automatic ways of thinking of planners, inhabitants as well as of real estate developers. Moreover, separation and fragmentation are the primary conditions and means by which this spatial logics preserves itself producing a constant process of colonization of new areas in order to replicate itself. This kind of urban space seems to be shaped to eradicate spatial differences and to communicate intolerance for it $[5,25-27]$.

Working under persistent opaque colonial logics produce and reproduce urban spaces that embody a close association between daily routine and urban reality, within routes and networks which link up the places set aside for work, private life, and localized leisure equipment. By reproducing the feature of a Latin-American colonial space, architects, planners or inhabitants are destined to continuously establish the most extreme separation between places and dwellers. Spaces for social life are almost impossible to achieve under these conditions. In this context, whenever urban reconfigurations, transformations or densifications are discussed in terms of functions or physical densities, in terms of quantities or indicators, the discussion has again left the realm of the social and entered onto that of the abstract $[1,27]$. [FIG. 03]. 

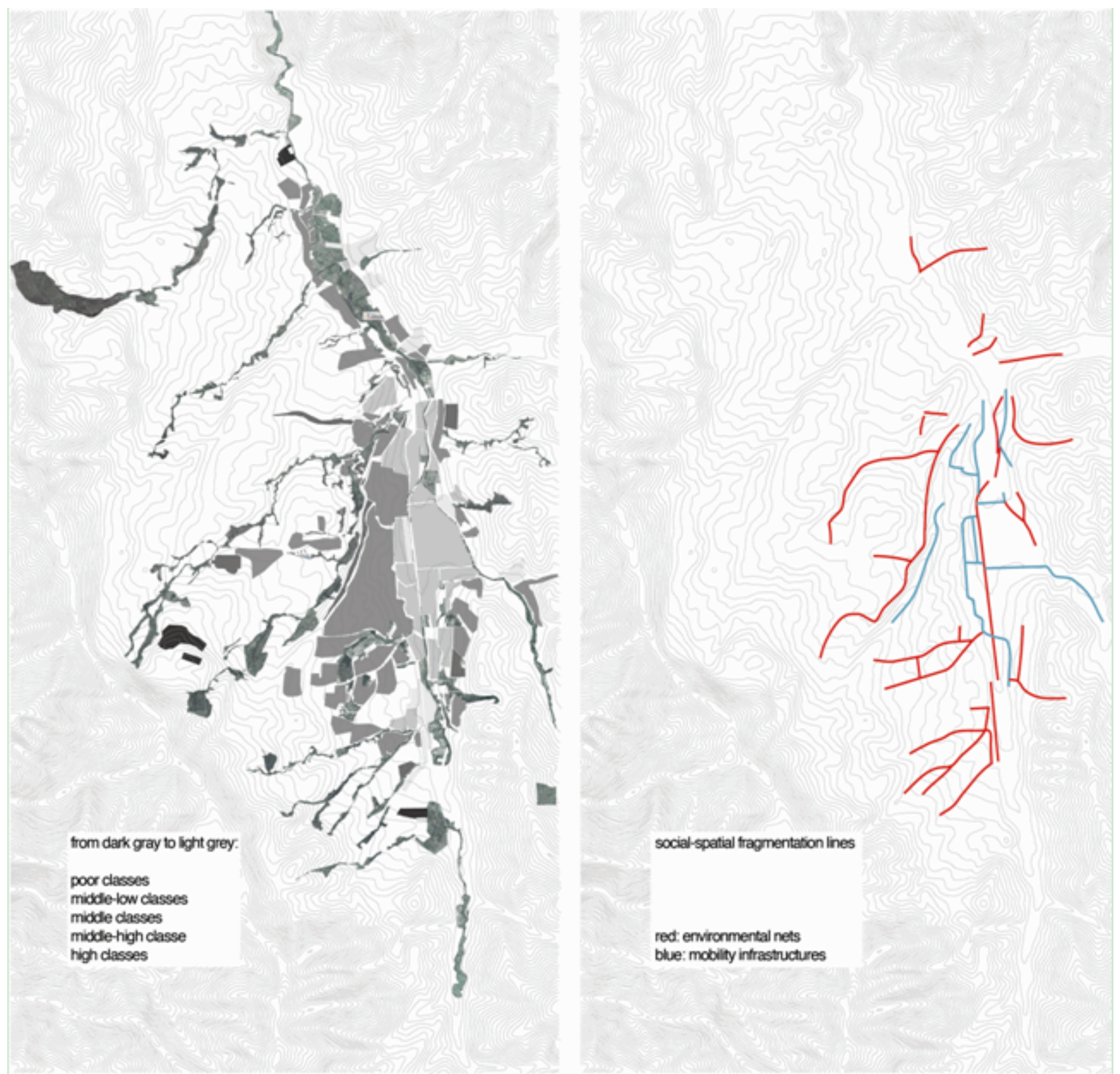

Figure 3. Social Segregation Lines

\section{Against the Native Grain. Counter-Projects}

The link between fragmentations of Ecuadorian middle cites and the persistence of colonial logics characterized by specialization, rarefaction, functional and social separation, is not coincidental, their association is inevitable. Thus, a truly alternative space would necessarily entail recapturing connections, redefining new 'densities', among dissociated elements and spaces.

There is in Loja an enduring concrete presence of 'counter-spaces' [28], and the persistence of certain modes of social life habituated to them. In neighborhoods such as Ciudad Victoria and Ciudad Alegria, parts of the urban environmental system, corresponding to hydrographic nets, are at the same time a residual and dangerous areas sometimes, unexpectedly, hosting interactions or social exchange practices by people coming from neighborhoods inhabited by different social classes. Here the presence of residual vegetable gardens foster some commercial activities; the steep slopes of the quebradas work at the same time as garbage dumps and as playgrounds where middle class and low class youngsters meet. In barrios such as Tierras Coloradas or Obrapia, the pattern of the grid is disturbed by spots of collective space functioning according to precise temporal rhythms, locally knowns as Canchas/Kanchas. These are rectangular dusty spaces dedicated to sports activities that work, especially during weekends, as 'social condensers', attracting, at its borders, social groups of different ages, trade and food sales. It is a kind of public 
space characterizing ancient pre-Columbian settlements that, under certain aspects, is still alive in contemporary Andean cities.

In these instable and poorly defined spaces, then, lies a possibility to construct new spatial codes where they lived, planned and perceived realms can be finally interrelated.

Main objective, then, in the re-qualification of Ecuadorian middle cities, is to define counter-projects, counter-proposals and counter-spaces. This task is a shift from a 'problematic of space', or the assertion of all-encompassing networks of explanations which are a direct expression of abstraction and reductionism in densification strategies, to 'spatial practices' [29, 30].

This approach throw into question the primacy of the visual realm in urban regeneration practices, i.e., densification as a quest for metropolitan images, and the graphic dimension which belongs, as one of its chief properties, to an abstract space, a space leading to a generalized state of deprivation.

Anyway it is important to acknowledge that articulating counterproposals and realizing them is no easy task. The obstacle faced by counter-plans or counter-projects may be enumerated. The most serious is the fact that on one side there are ranged resources and strategies on a vast scale while in opposition to these forces stand only limited knowledge and limited interests of generally medium-sized and small territorial spheres. All the same, the necessary innovations can only come out from interaction between projects and counter-projects, planning and counter-planning. It is only through these collisions that proposals for surpassing reality can be invented. It is an optimist attitude.

\section{Protocols of Loja}

A spatial and social recomposition of Ecuadorian medium-sized cities and a redefinition in most inclusive ways of the forms of dwelling and of social interaction at the proximity scale can be pursued through precise urban space densification strategies.
Talking about urban this specific theme, some clarifications need to be done.

Traditional meanings associated to the concept of urban density are related to current popular discourses such as economic sustainability, reduction of consumption of land, urban sprawl containment. These policies and design techniques are the outcomes of a set of researches and experiences absolutely important and highly relevant. These densification strategies, however, in these contexts, seem able to solve only few problems, mainly related to questions of compactness of urban space, mixité or co-presence of multiple functions, improvement of urban landscapes. These are forms of densification that trigger virtuous uses of abandoned or underutilized urban spaces, reducing problems of small-scale mobility, relieve the demand for social housing, but, under many aspects, these strategies seem not address directly some relevant issues, social conditions and dwelling practices characterizing contemporary Ecuadorian middle cities [31-39].

Alternative ideas about urban densification strategies, then, can be defined focusing on the experimentation and the invention of particular devices space of social interaction characterized by a superposition of uses and functions able to define dense forms of use in actually residual spaces. The configuration of these devices will make the urban mosaic of medium-sized cities more livable and inclusive, configuring a geography of places designed as 'membranes' ${ }^{\text {ii }}$ spaces between neighborhoods inhabited by different social classes. The devices are located within the lattice environmental system, quebradas or minor hydrographic nets, actually working as barriers, contact zones or interface zones, between neighborhoods inhabited by different social classes. These in-between linear spaces may be considered as potential sites of subversiveness precisely because the positive rendering of the gaps it describes simultaneously links and separates opposed conditions in just the ways that overly rationalized urban patterns attempt to erase. [FIG. 04]. 


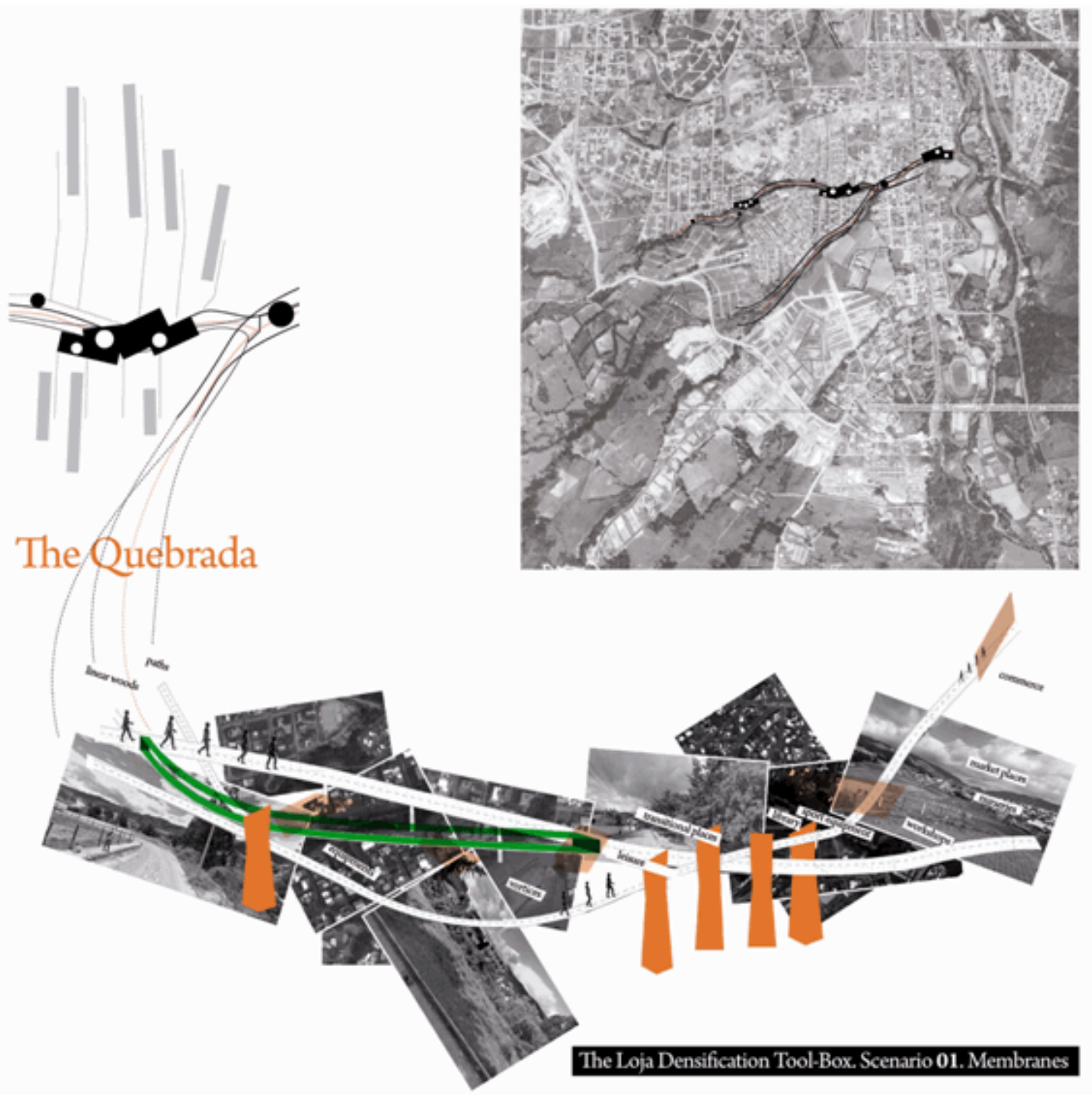

Figure 4. The Quebrada

Devices and correspond to systems of spaces conceived in section as a sequence of layers that hosts functions and possibilities of use that can be very different: sports equipment, gardens, commercial spaces, nurseries, small craft workshops, recreational areas, schools. Such sequences of layers may correspond to interiors, open spaces or to transitions between inside and outside. These device are physically designed as a sequence of narrow ribbons diluted along the articulations of the environmental system. From the environmental point of view, these 'membranes' are themselves hydraulic machines able to collect and purify rainwaters and waste-waters connecting themselves and improving the ecology of the quebradas.

This strategy of densification neither correspond to an attempt to make the existing urban fabric more porous or functionally mixed, nor it is not based on the adoption of European public space models such as squares, boulevard or arcades. This strategy accepts the functionalist and, in some ways, 'hypermodern' character of this urban space, inserting densification devices in the contact zones between today socially and spatially separated neighborhoods. In the identification and configuration of these devices a central role is therefore given to the upgrading of the environmental network that is redefined in some of its parte as a 'membrane', a contact and and social interaction zone between parts of the city and social groups now separated from each other, inventing new ecological qualities and features.

This particular strategy of densification intended as consolidation and intensification of borders of existing neighborhoods identifies a number of new public open spaces, public facilities, and spaces for leisure, commerce and labor, intended as social and environmental interaction devices.

These devices may have from time to time a semi-public, communitarian or fully public character.

A membrane is a selective barrier, not a smooth open surface. It allows some things to pass through it but stops others. In this sense it may acquire the structure and character of an urban interior crossable by subjects, 
functions, processes.

The result is the definition of a number of innovative 'social condensers', central places able to host a variety of social exchange process related to leisure, commerce, work or sport activities, which will help reduce the current center-periphery commuting movements and able to reinterpret the friction between the abstract grid informing the existing urban fabrics and the residual environmental system. The definition of these spatial devices will redefine in more inclusive way relations between districts inhabited by different social classes, increasing urban comfort qualities.
These devices will finally help an incremental physical densification process in its surrounding neighborhoods as its inhabitants with adequate centralities, urban comfort conditions, workspaces and leisure time equipment will trigger processes of incremental residential modifications. In the Latin American incrementalism tradition, characterized by progressive housing strategies and and participatory design to architecture and urban development, it is possible to see how well-equipped neighborhoods evolve in a definitely physically dense and socially rooted way. [FIG. 05], [FIG. 06], [FIG. 07].

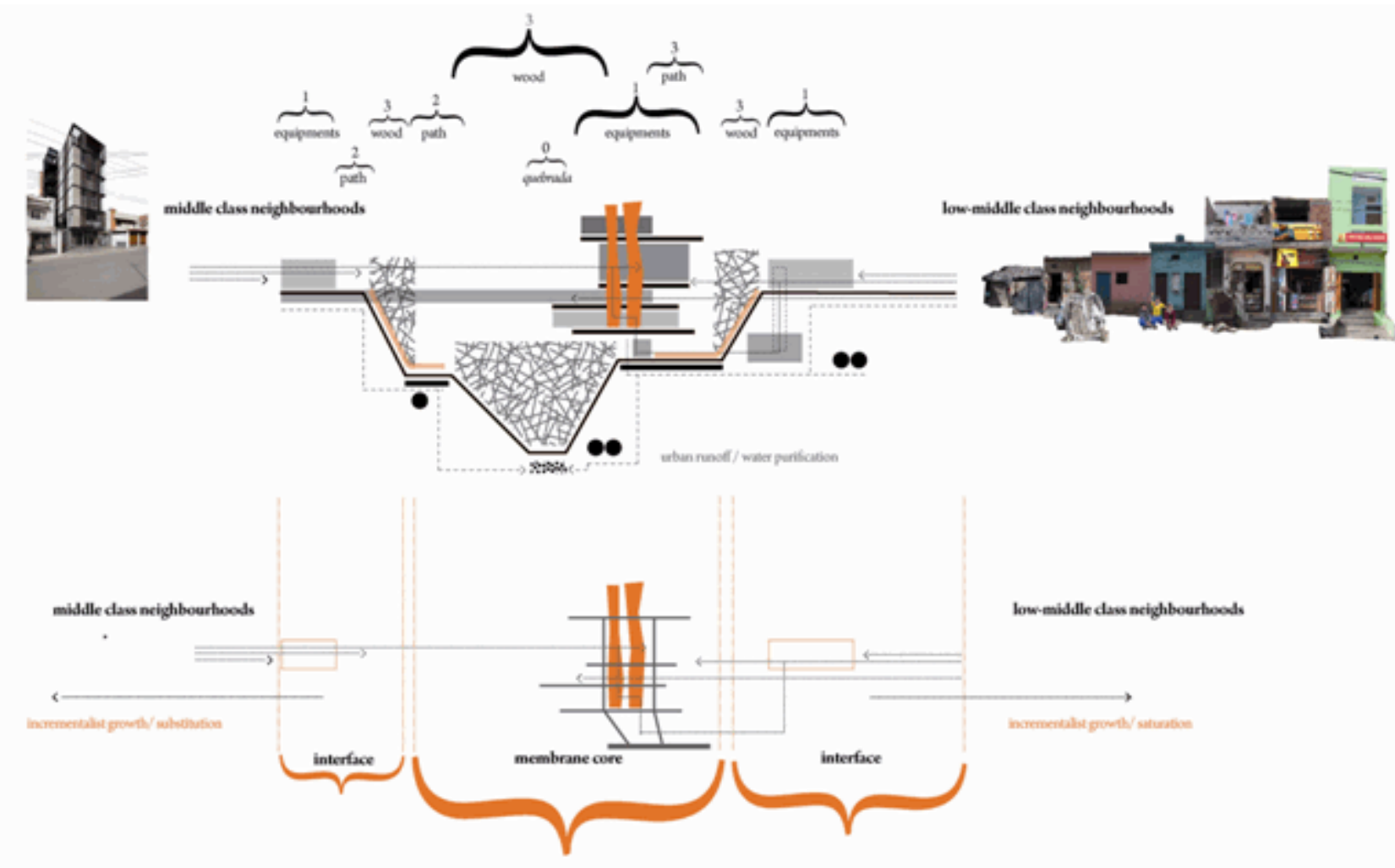

\section{Diagram}
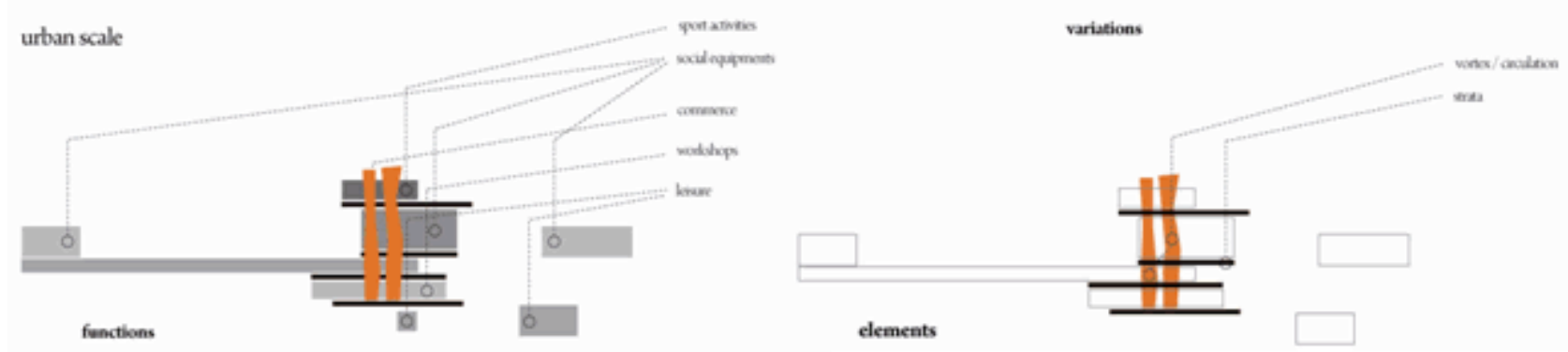

The Loja Densification Tool-Box. Scenario 01. Membranes

Figure 5. Scenario. Membranes 

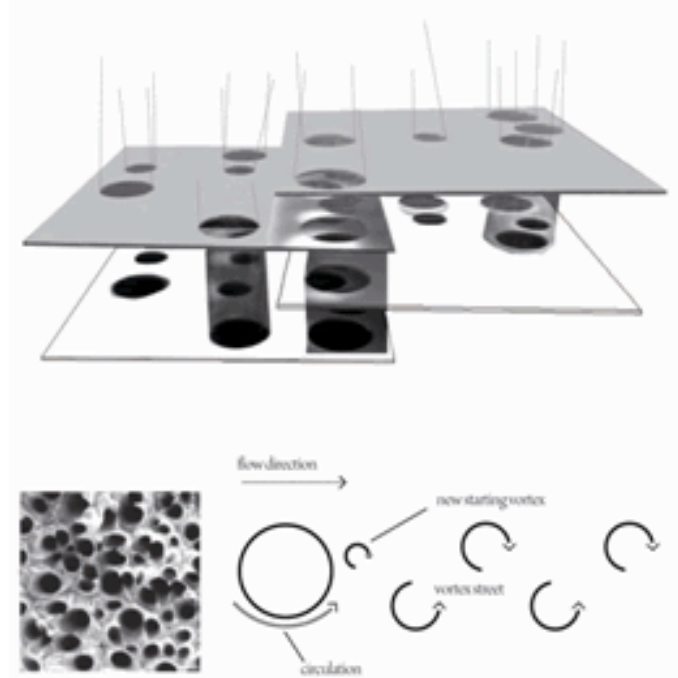

spatial cencepe

The membane is a mactinellike utun device that nepponds dymamically to the life of the

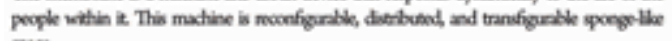
space.

\section{Vortices and Boxes}

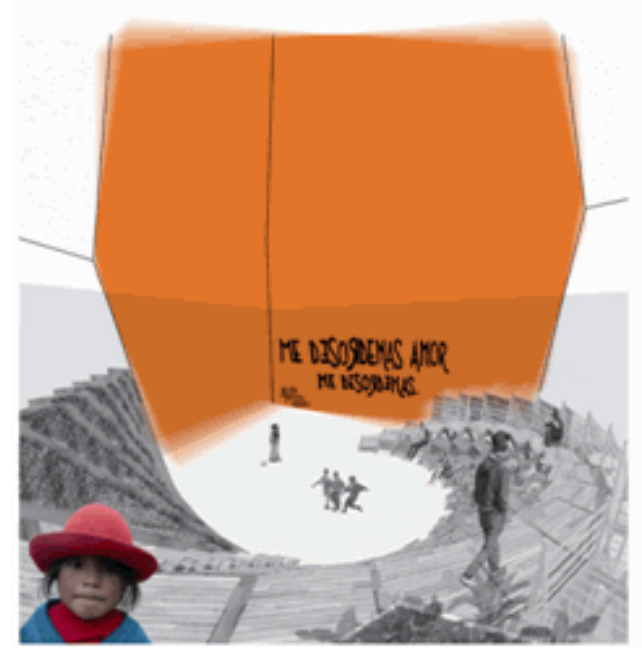

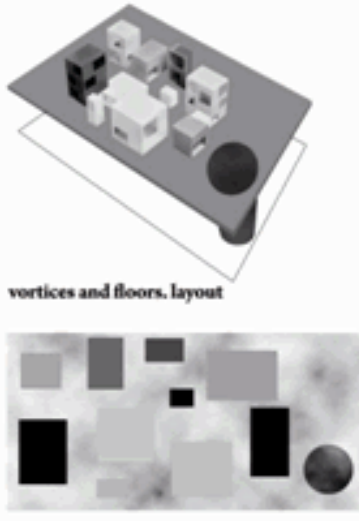
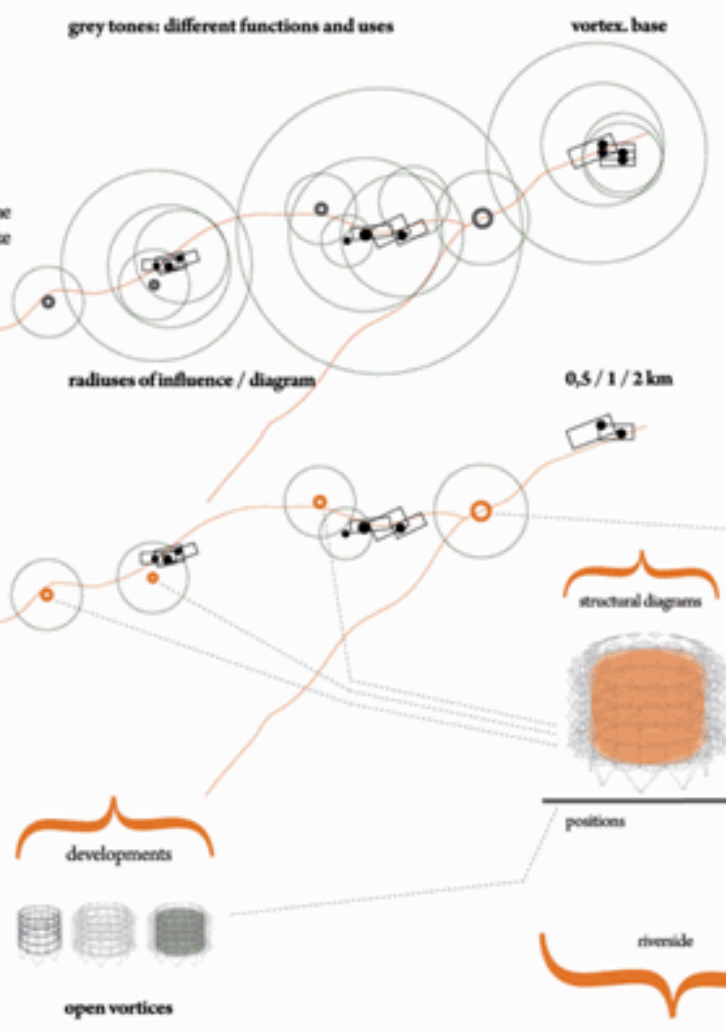

$0,5 / 1 / 2 \mathrm{~km}$
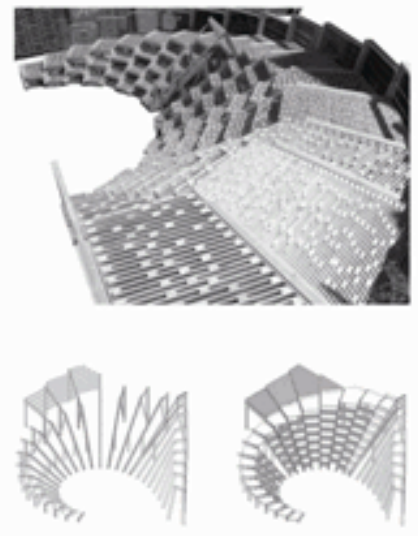

(n)

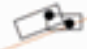
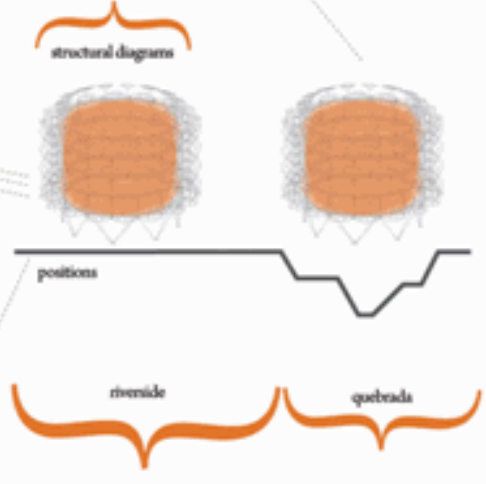

The Loja Densification Tool-Box. Scenario 01. Membranes

Figure 6. Scenario. Membranes: Vortices and Boxes 
Actual Density:

25 dwellings/

66hab/h

COS/Coverage: $20 \%$

CUS/FSI,Floor Space index: $43 \%$

Future Density:

60 dwellings/ha

240 hab/ha

COS/Coverage: $49 \%$

CUS/FSI,Floor Space index: $110 \%$

\section{Densification}

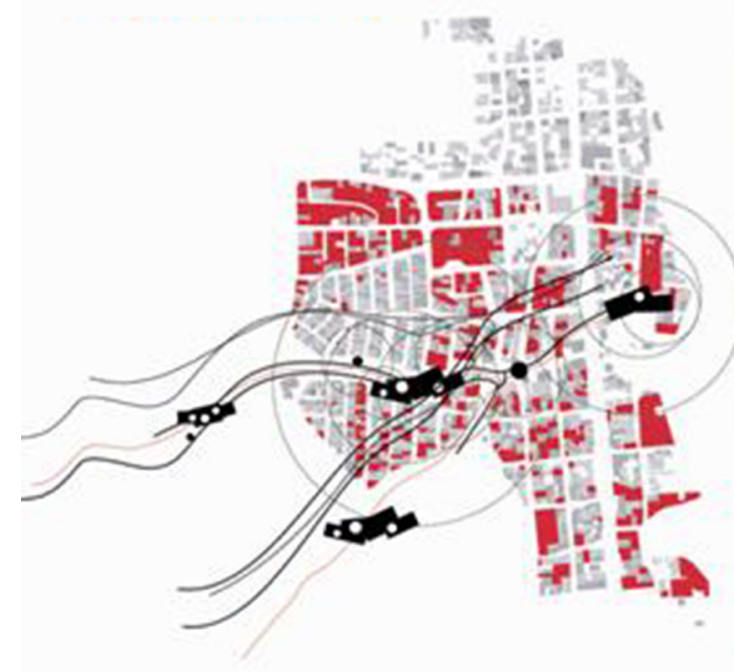

incremental densification/ increased density
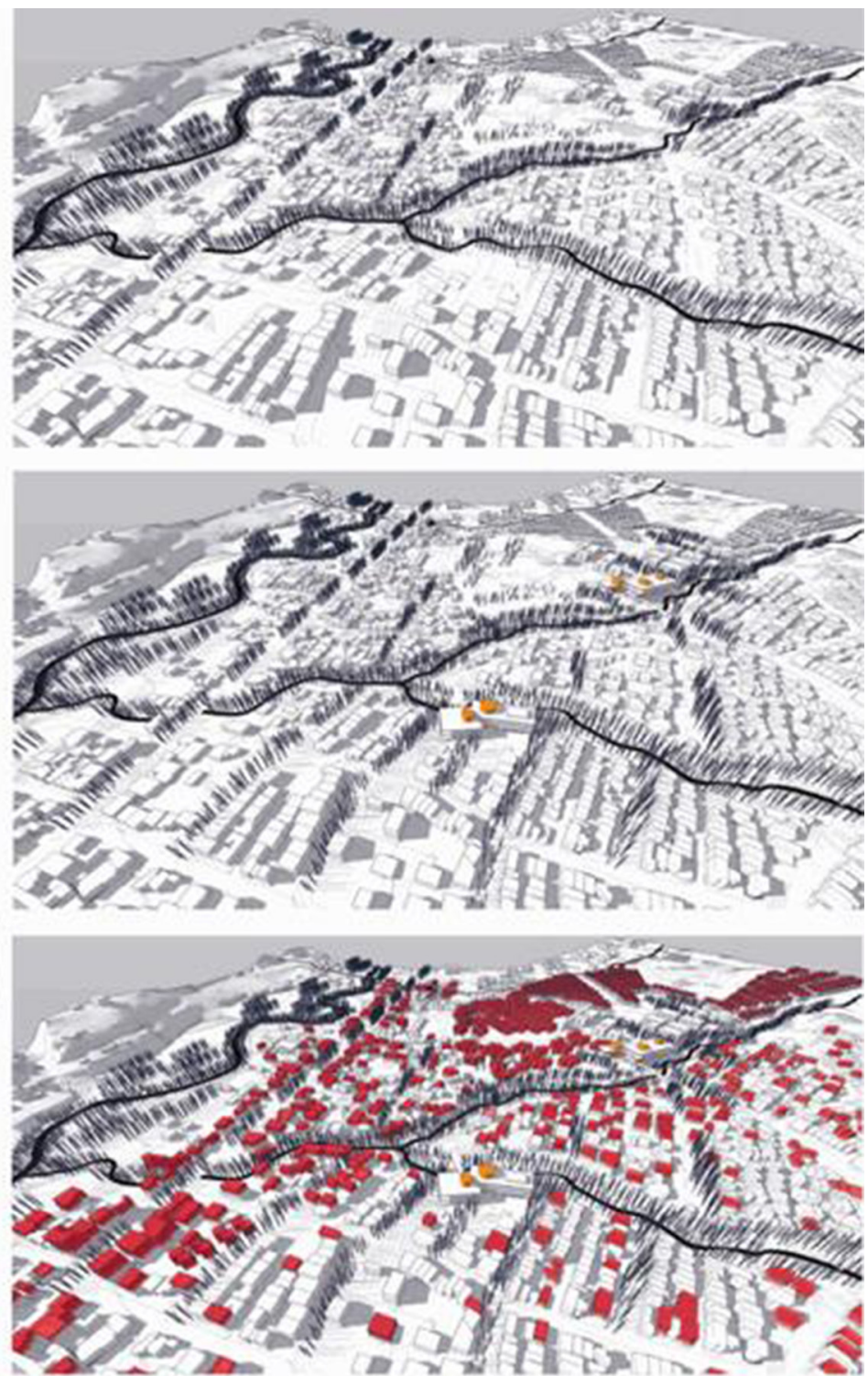

The Loja Densification Tool-Box. Scenario 01. Membranes

Figure 7. Scenario. Membranes: Incremental Urban Densification Process

In the persistent colonial dwelling tradition characterizing these territories, inhabitants when they improve their economic or social conditions, move into richer district. In this sense, the strategy of densification here proposed is an attempt to question and criticize this attitude of un-rootedness.

Densification, definitely, here is understood as a series of counter-projects defining protocols of consolidation and intensification of uses and social exchanges more than increasing of volumes or inhabitants per hectare.

These counter-projects presuppose a collective ownership and self-management of space founded on the permanent participation of the interested parties with their multiple, varied, and even contradictory interests, skills and visions. It thus also presupposes confrontation. The counter-project helps to surpass separations and dissociations between social groups, spaces and finally times. On the horizon, then, it is not a matter of quantities of dense urban fabrics, rather it is a matter of producing space capable to redefine dwelling practices at the proximity scale in a more just and inclusive way. These counter-projects represent a challenge of a utopian sort, and utopia of real projects reliant on an orientation rather than a system for their emergence.

\section{REFERENCES}

[1] H. Lefebvre. The Production of Space, Wiley, Oxford, 1992. 
[2] M. Foucault. L'ordre du discours, Gallimard, Paris, 1971.

[3] M. Foucault. Surveiller et punir. Naissance de la prison, Gallimard, Paris, 1975.

[4] A. Gilbert. The Latin American City, Latin America Bureau, London, 1994.

[5] M. Davis. Planet of Slums, Verso, London, 2007.

[6] J. Kinsbruner. The Colonial Spanish-American City: Urban Life in the Age of Atlantic Capitalism, University of Texas Press, Austin, 2010.

[7] P. Franko. The Puzzle of Latin American Economic Development, Rowan \& Littlefield, Plymouth, 2007.

[8] G. M. Joseph and M.D. Szuchman. I Saw a City Invincible: Urban Portraits of Latin America, Rowman \& Littlefield, Plymouth, 1995.

[9] J. Beall, R. Kanbur, D. Rodgers (eds.), Latin American Urban Development into the Twenty First Century, Palgrave Macmillan UK, 2012.

[10] F. Carrión. La ciudad construida. Urbanismo en América Latina, Flacso, Quito, 2001.

[11] R. Gutiérrez. Pueblos de indios: otro urbanismo en la región andina, Abya-Yala, Quito, 1993.

[12] T. Cummins and J. Rappaport. Beyond the Lettered City: Indigenous Literacies in the Andes, Duke University Press, Durham, 2012.

[13] H. Orbea Trávez. Interview, Quito, 17 November 2014.

[14] A. di Campli. Espacios criollos, Traza. n.2, CO: Publicaciones Unisalle, Bogotà, 2011.

[15] J. Perlman. Favela: Four Decades of Living on the Edge in Rio de Janeiro, Oxford University Press, New York, 2010.

[16] J. Bredenoord, P. van Lindert and P. Smets (eds.). Affordable Housing in the Urban Global South, Routledge, New York, 2014.

[17] R. Burdett. Uneven Growth: Tactical Urbanisms for Expanding Megacities, the Museum of Modern Art, New York, 2014.

[18] J. Lerner. Urban Acupuncture. Celebrating Pinpricks of Change that Enrich City Life, Island Press, Washington, 2014.

[19] J. McGuirk. Radical Cities: Across Latin America in Search of a New Architecture, Verso, London, 2015.

[20] Centro ecuatoriano de investigación geografica. El Manejo del espacio en el Ecuador: etapas claves, IGM de Ecuador, Quito, 1983.

i The reference to the kind of regular trace used by Hernan Cortez in the refunding of Mexico City overlapped to the fabric of the old Aztec city of Tenochtitlan.

ii The reference is to the concept of creolisation and membraneous politics as developed by the French philosopher Yves Citton.
[21] Centro ecuatoriano de investigación geografica. El espacio urbano en el Ecuador. Red urbana, región y crecimiento, IGM de Ecuador, Quito, 1986.

[22] C. Klaufus. Construir la ciudad andina: planificación y autoconstrucción en Riobamba y Cuenca, Abya-Yala, Quito, 2009.

[23] A. Ouweneel (ed.). Andeans and and Their Use of Cultural Resources Space, Gender, Rights \& Identity, CEDLA, Amsterdam, 2012.

[24] H. Lefebvre. Le droit a la ville, Anthropos, Paris, 1968.

[25] R. Park. On Social Control and Collective Behavior. Chicago, 1967.

[26] M. Balbo. 'Urban Planning and the Fragmented City of Developing Countries', Third World Planning Review, vol. $15,1,1993,23-35$.

[27] H. Lefebvre. Writings on Cities, Blackwell, Oxford, 1996.

[28] E. Soja. Seeking Spatial Justice, University of Minnesota Press, Minneapolis, 2010.

[29] P. Bourdieu. Distinction: A Social Critique of the Judgement of Taste, Routledge, New York, 1984.

[30] M. de Certeau. The Practice of Everyday Life, University of California Press, Berkeley, 1984.

[31] A. Amin and N. Thrift. Cities: Reimagining the Urban, Polity, Cambridge, 2002.

[32] Amphoux, P., Heynen, H., Vanderburgh, D. and Vöckler, K. (2003) Inside Density: International Colloquium on Architecture ans Cities \#1 (La Lettre vole, Carouge).

[33] R. Bruegmann. Sprawl: A Compact History, University of Chicago Press, Chicago, 2005.

[34] R. Koek, W. Maas and J. van Rijs (eds.). MVRDV: FARMAX Excursions on Density, nai010 Publishers, Rotterdam, 2013.

[35] MVRDV. KM3-Excursions on Capacities, Actar, Barcelona, 2006.

[36] H. Schramm. Low Rise High Density Horizontale verdichtungsformen im Wohnbau, Springer, Wien, 2008.

[37] J. Gehl. Life between Buildings: Using Public Space, Island Press, Washington DC, 2011.

[38] S. Bates and J. Sergison. High-Rise, High-Density, Harvard University Graduate School of Design, Cambridge, MA, 2014.

[39] E. Tröger. Density \& Atmosphere, Birkhäuser, Basel, 2014. 